\title{
Superior Performance of Leagile Supply Networks by Application of Autonomous Control
}

\author{
Bernd Scholz-Reiter and Afshin Mehrsai \\ c/o BIBA GmbH, Hochschulring 20, \\ 28359 Bremen, Germany \\ \{bsr, meh\} @biba.uni-bremen.de
}

\begin{abstract}
In the paper, a special approach to supply networks' material flows is posed. The considered strategy is based on the both principles of Lean and agility, beside push and pull of materials. Here, the trade off between positioning of decoupling point throughout an exemplary network, and reduction of inventory level along throughput time is examined. Moreover, autonomous control for material routing and lot-sizes is taken into account. To do so, a discrete-event simulation model is developed to show the performances.
\end{abstract}

Keywords: Leagile, Production Network, Autonomous Control, Dynamic.

\section{Introduction}

Dynamic complexities, constraints in performances, interactions between heterogeneous interests, competitions, and requirements in the current business environment force enterprises to undertake more innovative strategies for their supply chains. This should be done in order to meet customized demands in markets on time with less cost to keep own market share or even expand it.

To be on time and cost efficient in performances are two competitive necessities at the present market circumstance. While enterprises move toward cost efficiency, they are pledge to meet customer demands at the right time with their exact customized requirements [1]. From an isolated enterprise to broader scales like supply networks, several disparate performance targets confront enterprises with several difficulties to coordinate their effective processes. For instance, reductions in time and cost of production activities have been considered as two incongruent targets for supply chains (SC).

In general, two production approaches exist; mass production and mass customization. In case of mass production the higher priority was with cost reduction and other activities had to be aligned to comply with that objective. On the contrary, in mass customization (i.e., the ability of manufacturer to quickly design, produce and deliver product to the customer with its specific requirements by the lowest possible price), time reduction and responsiveness beside reduction in cost are taken into account [2]. In fact, cost reduction is a result of time efficiency and agility in performances.

Normally, mass production is based on make-to-stock (MTS) strategy, which by clustering the production activities in a straightforward format (distinct from its inventory cost), causes less effort for production of the same products and consequently 
reduction in finished cost. On the other hand necessity of customizing products according to customer needs bring about the requirements of becoming enough flexible, agile, responsive, effective, and also efficient in supply networks. In contrast to mass production, mass customization seeks built-to-order (BTO) or assemble-to-order (ATO) strategies for fulfilling customers. Yet, employment of the both approaches, simultaneously, throughout a supply network is possible. For the mentioned purposes, it requires some arrangements to configure such a network. Modular design of products, flexible resources [3], agility, and positioning of a decoupling point (DP) between front-end (with MTS strategy) and back-end (with ATO strategy) [4], are some of those arrangements. These types of hybrid networks are known as leagile supply networks that combine two material flow strategies; push of the materials with the same platform up to DP, while pulling of semi-finished products according to customers' customized orders.

In a supply network, members from several tiers, and via a virtual network, are closely connected to each other. This brings coordination and integration to their logistics processes. Monitoring of inter- and intra- organizational processes causes better accomplishments throughout the network in terms of material and information flow [4]. However, this integrity and high volume of information exchange in a mass customized system leads to another problem which is complexity and overloading in information analysis as well as less flexibility for members.

Autonomous control is a new approach to decline the complexities of information mass processing. Although the input information to an autonomous object (e.g., products, machines, transporters) could be a collection of data about global and local targets, but the decision maker is the object itself and no hierarchy dominate that. In general, autonomous control means: "a decentralized coordination of intelligent logistic objects and the routing through a logistic system by the intelligent objects themselves" [5]. Regarding the characteristics of autonomous systems, this state-of-the-art is assumed suitable to realize customized systems' goals.

In the paper, firstly, it is addressed the features of supply networks as well as its contribution to mass customized products. Secondly, autonomous control vs. conventional planning will be discussed. Thirdly, the simulation scenario is introduced and the results are compared. Finally, followed by the results the conclusion is explained.

\section{Supply Networks}

Markets environment, competitions, scarce resources, globalization, and requirement of the right product to the right customer within the right time by the lowest cost, persuade organizations to go toward managing their supply networks instead of optimizing their own processes. Today, there is no isolated organization which is successful in the market. That led to higher integration between supply networks and consequently appearance of the art of supply chain management (SCM). Focusing on logistics processes and transportation, SCM interpreted as integrated logistics systems. Thus main concentration is on inventory reduction both within and across organizations in supply networks [6].

Integration between members of supply chains brings about higher complexity in terms of processes' coordination. Simply, consideration and coordination of all effective processes of a supply network burden a tough controlling task to the entire 
network. Moving from the initial concept about supply chain management, which considers intra and inter-organizational processes, some new approaches exist. They try not to integrate and coordinate all effective units' processes, but just the interfacing processes to get the global consistency. In this approach the members or units of the network perform autonomously in their internal processes [4]. This tactic decreases the existing complexity of entire networks' coordination.

It is noticeable that supply chains are usually assumed as series of suppliers and manufacturers aligned in a successive order. Nonetheless, supply networks address those supply chains that configure some networks via virtual interconnections rather than configuration of successive unites. Here supply chain and network could be used alternatively.

\subsection{De-coupling Point}

In a system with modular products, procurement of materials is going to be easier. Final products are constructed based on similar (even the same) platforms with just some variations in final assembly. This contributes to the both requirements of customization and efficiency of products [12]. In addition, the supply network could benefit from this modularity by allocating two different strategies to two sides of its chain. This will be happened by application of postponement concept. Postponement could be explained as differentiation of products' types at the closest point to the customer [13].

Separation of supply networks, into two divisions of material push and material pull, makes a drop in complexity of information and material flow. By means of this strategy, demand's information penetrates from downstream of the chain up to a specific level of supply chain. This point called information DP. However, there exists another DP that separates the flow strategy of goods and called material DP [7], [8]. Both DPs could be shifted from downstream of a SC to upstream of that concerning the product varieties, types and SC structure. Necessarily, information DP and material DP are not coupled in the same location of a supply network.

\subsection{Leagility}

In those supply networks with the capability of decoupling, employment of two outstanding capabilities as lean and agile principles is facilitated. According to some literatures [9], [10] from upstream of a chain to the material DP, members are persuaded to follow lean principles into their processes and sustain the waste reduction and value adding activities. On the other side, downstream from material DP should be responsive and flexible to customized demands. Therefore, here, the agile principles are sought by networks [11]. Agility has been introduced to bear required flexibility and responsiveness in term of real-time constraints and demands to the system. Such a favorable combination of two material push-pull strategy as well as lean-agile principles configures leagile networks with the profits of both concepts.

Positioning of material DP in a network, moving from adjacency of final customer toward the upstream of the network, means expanding material pull principle from downstream customers and shrinking of material push from the upstream plants. Obviously, location of this point has a remarkable effect on supply chain performance measures like: throughput time (TPT), WIP, and responsiveness [19]. 


\section{Autonomy}

Current supply networks are configured based on coordination of operations and integration of decision makings amongst autonomous units of the network. This context gives flexibility to SC and their members to make their own decisions, while the entire performance complies with global goals of the network [14].

In general, the outbound logistics of SC should disseminate the effective information to the members in order to integrate them to achieve final customer satisfaction. However, autonomy for members and logistics objects seems to be a practical solution for reducing accompanied complexities in supply networks with customized market. Autonomous control for logistics objects is an absolute heterarchical structure; thereby entities with gathering local information act upon global targets of the logistics system. So far, for this imminent structure, some routing control methodologies have been introduced that give the ability to moving units to find their routes through a logistics network, according to some local information and metrics. Among them are queue length estimator (QLE), ant colony, bee's foraging, and due date [15], [16], [17], [18]. Autonomous control (Aut) normally is explained against conventional ${ }^{1}$ systems (Conv).

QLE is an autonomous routing control method that accommodates autonomous objects with the competency of estimating their following queues and bottlenecks. By comparing the alternative routes or destination for producing purposes, the one with the lowest processing and waiting time will be chosen by the autonomous object itself.

Furthermore, autonomous control is not limited to routing in production or logistics networks. Flexible lot-sizes (Varlot) and intelligent pallets (IP) from the material DP (the interface of push and pull of materials) bring superiority to leagile networks according to the general performance measures of logistics. In particular, autonomous pallets are in the way of individualization of products in a material pull principle system. Individualization in mass customized systems has a crucial roll to superior operations and results [3], [4].

\section{Simulation Scenario}

For evaluating the performance of autonomous control for products and pallets as logistics' objects, a discrete-event simulation approach is considered. A simple model of a supply network, with push and pull of materials, is developed to represent a leagile network. For simulating the pull system a special conwip control system is set up here [20]. The network is constructed of two similar source plants in the upstream $\left(\mathrm{P}_{11}, \mathrm{P}_{12}\right)$, two assembly plants with similar capabilities $\left(\mathrm{P}_{21}, \mathrm{P}_{22}\right)$ and one original equipment manufacture (OEM). Within this network, three types of final products are delivered to final customers. Each final product is assembled of two parts that each of them is produced in either sour plant. The final three types of products are pulled by customers within a seasonal effect manner. To simulate this effect a sinusoidal equation is considered as demand rate (1) that each type has a 1/3 phase shift. In order to realize the total flexibility for the supply network, both source plants are connected to

\footnotetext{
${ }^{1}$ Conventional systems: Those dispatching systems of product types based on pre-defined production schedules, regarding general constraints, available capacities and stations' cycle times.
} 


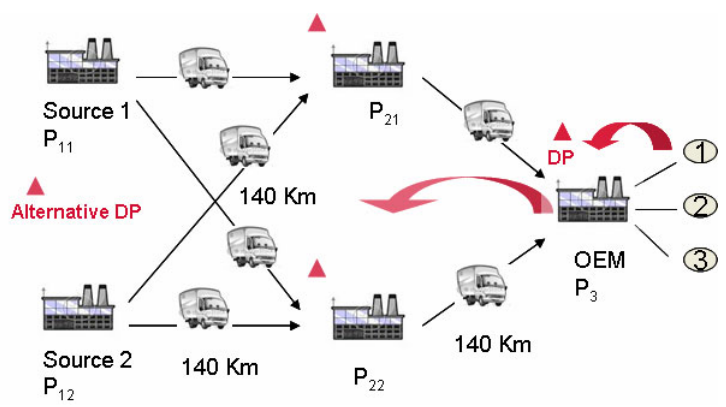

Fig. 1. Exemplary leagile supply network. Each distance is assumed as $140 \mathrm{~km}$ which is connected via one transporter. Each round trip takes 4 hours for transporters [20].

the both assembly plants, respectively, both assembly plants are connected to OEM. Fig. 1 shows the structure of outbound logistics in this supply network.

Based on a developed model of Scholz-Reiter et al. [18], the inbound logistics' structure for source $1 / 2$ as well as OEM, is constructed of three production lines, each consist of three similar stations. This makes up a $3 \times 3$ matrix of stations. To configure a flexible structure, for facilitating autonomous control, every station in the same column is coupled with their successors (see Table 1 for times).

The respective autonomous control for routing the intelligent products and pallets is QLE [5]. This method is taken because of its simple performance to understand and realized.

In addition to routing control, here, pallets in OEM (with pull of material) have the capability to assess the rate of demand versus rate of pushing materials. This aptitude gives the pallets the ability of pro-activity. These proactive pallets continuously get the ratio of demands to upcoming products. In fact, the pallets, between the intervals of coming demands, compare the average of last five intervals of demands with the last five intervals of coming semi-finished products into the entrance of OEM. When the ratio is over one this means the demands are ordered with a higher rate than before. Since over one ratio is kept, respective pallets will be loaded to the entrance of the OEM, to collect the respective product, without any direct demand order.

Table 1. Considered processing times for each product on each line at $\mathrm{P}_{11} ; \mathrm{P}_{12} ; \mathrm{P}_{3}$ and assembly plants $\mathrm{P}_{21} ; \mathrm{P}_{22}$. The min processing times are equal to the mean intervals of emerging products.

\begin{tabular}{|c|c|c|c|c|}
\hline & \multicolumn{4}{|c|}{ Processing times [h:min] for each plan } \\
\hline \multirow[t]{2}{*}{ Plant } & \multicolumn{3}{|c|}{$\mathrm{P}_{11} ; \mathrm{P}_{12} ; \mathrm{P}_{3}$} & $\mathrm{P}_{21} ; \mathrm{P}_{22}$ \\
\hline & \multicolumn{4}{|c|}{ Line } \\
\hline Product & 1 & 2 & 3 & 1 \\
\hline Type 1 & $2: 00$ & 3:00 & $2: 30$ & $1: 00$ \\
\hline Type 2 & $2: 30$ & 2:00 & 3:00 & $1: 00$ \\
\hline Type 3 & $3: 00$ & $2: 30$ & 2:00 & $1: 00$ \\
\hline
\end{tabular}


However, from sources to OEM, as the main warehouse in the network, products are pushed with two scenarios; first, with similar seasonal manner to demand with the same sequence. The second scenario is random push and pull of each product type in both upstream and downstream. The random numbers are accompanied with normal distribution with $\mu=50 \mathrm{~min} \sigma=5 \mathrm{~min}$ for the intervals between each upcoming same product and with $\mu=2: 30 \mathrm{~h} \sigma=30 \mathrm{~min}$ demand.

$$
\lambda(t)=0.4+0.15 \sin (t+\varphi)
$$

\section{Simulation Results}

Following graphs and bar chart are depicted to illustrate the comparison of logistics performance under Aut and Cont systems.

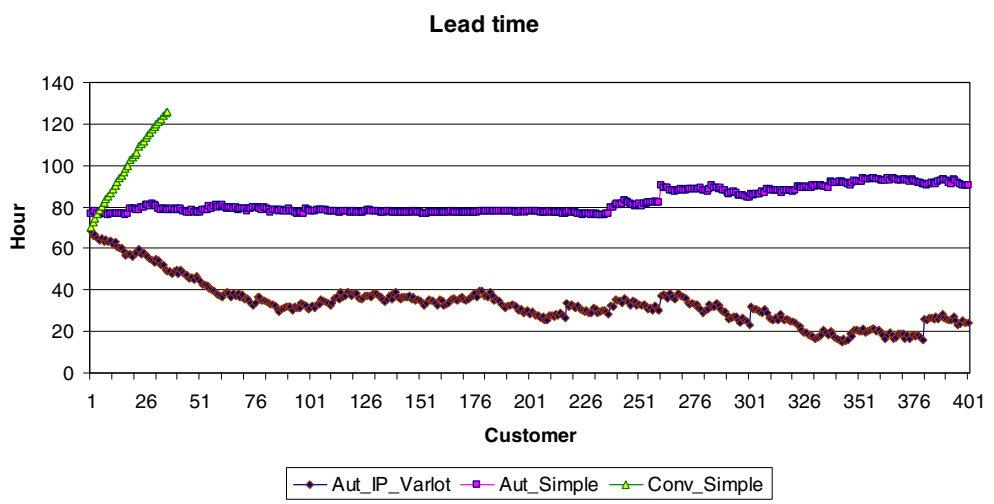

Fig. 2. Comparison between customer lead times under Conv routing, Aut routing and Aut with IP and Varlot

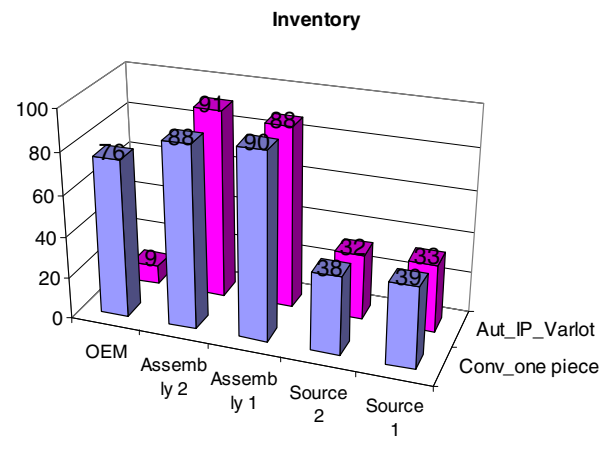

$\square$ Conv_one piece $\square$ Aut_IP_Varlot

Fig. 3. Inventory comparison between five plants; under Aut with IP and Varlot, and Conv with one piece flow. Both push and pull of materials are subject to seasonal effect (1). 


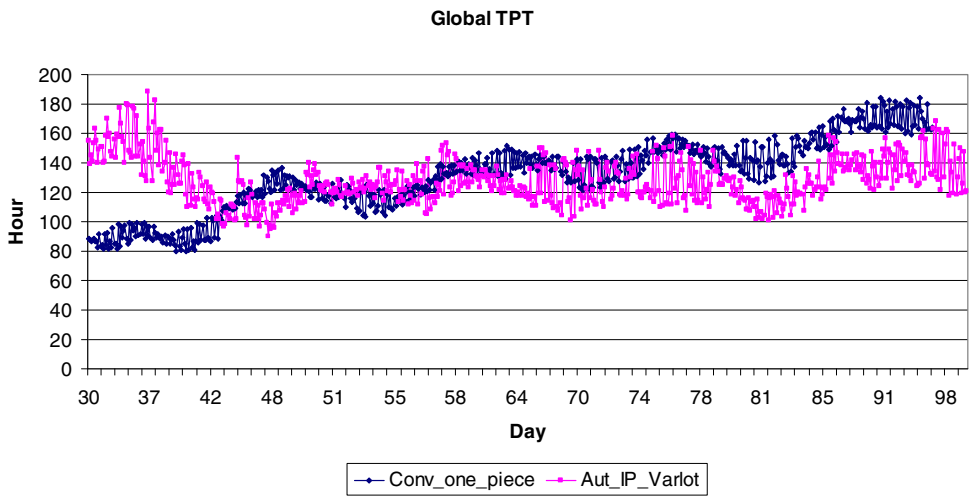

Fig. 4. Global throughput time (TPT) of products starting from source and terminating after OEM. Comparison under Conv and Aut with IP and Varlot.

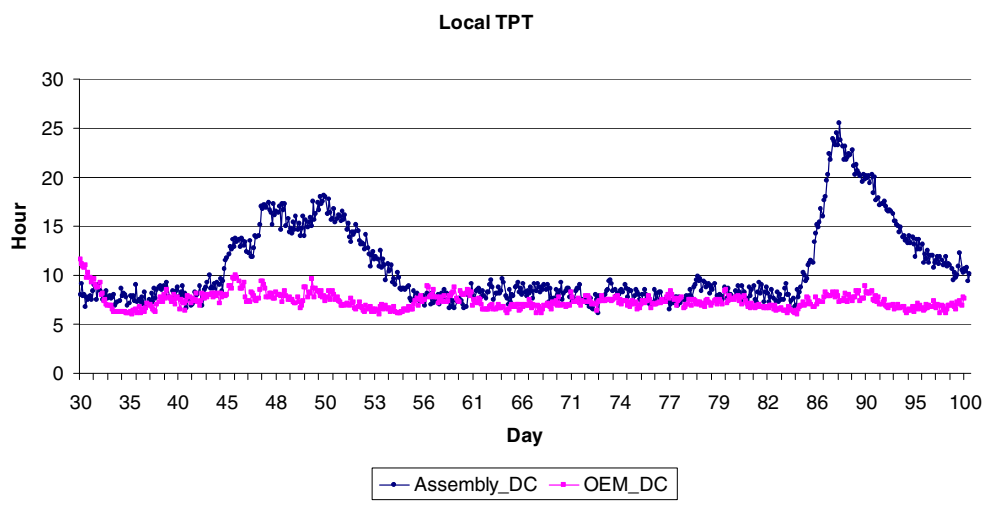

Fig. 5. Local TPT in OEM when the DC is positioned before OEM, and when before Assembly stations

\section{Conclusion}

In conclusion, simulation results already appeared that the autonomous control in routing has several pluses to logistics performance in comparison with conventional planning. This was proved before under different scenarios. Furthermore, variable lotsizes and proactive pallet in pull systems (assumed the conwip system works with pallet) proved its contribution to superior performance of logistics measures. Although just TPT, customer lead time, and WIP were used as logistics criteria, but some other metrics should be considered for evaluating the real contributions of methods and technologies.

Here was shown that closer DC to final customer shorter local TPT for end plant, and respectively shorter lead time is resulted. By postponing the consolidation of final product, inventory volume before DC and the stress for individualization decreases. 
Nonetheless, for every scenario, DP should be positioned according to constrains in terms of warehouses, postponement capability, and customer patience. The paper assumed a very simple method for proactivity and autonomy. However, as further research potentials, new methodologies not only for routing control, but for proactive and intelligent pallets seem to be a very feasible approach in pull principle systems.

\section{References}

1. Whicker, L., Bernon, M., Templar, S., Mena, C.: Understanding the relationships between time and cost to improve supply chain performance. Int. J. Production Economics (2006), doi:10.1016/j.ijpe.2006.06.022

2. Tu, Q., Vonderembse, M.A., Ragu-Nathan, T.S.: The impact of time-based manufacturing practices on mass customization and value to customer. J. of Operation Management 19(2), 201-217 (2001)

3. Fredriksson, P., Gadde, L.E.: Flexibility and rigidity in customization and built-to-order production. Industrial Marketing Management 34(7), 695-705 (2005)

4. Romano, P.: Co-ordination and integration mechanisms to manage logistics processes across supply networks. J. of Purchasing \& Supply Management 9, 119-134 (2003)

5. Scholz-Reiter, B., Jagalski, T., de Beer, C., Freitag, M.: Autonomous Shop Floor Control Considering Set-up Time. In: Proc. of 40th CIRP International Seminar on Manufacturing Systems, Liverpool, UK, pp. 1-6 (2007)

6. Li, S., Ragu-Nathan, B., Ragu-Nathan, T.S., Subba Rao, S.: The impact of supply chain management practices on competitive advantage and organizational performance. J. of Management Science, Omega 34, 107-124 (2006)

7. Mason-Jones, R., Towill, D.R.: Using the Information Decoupling Point to Improve Supply Chain Performance. Int. J. of Logistics Management 10(2), 13-26 (1999)

8. Sun, X.Y., Ji, P., Sun, L.Y., Wang, Y.L.: Positioning multiple decoupling points in a supply network. Int. J. Production Economics 113, 943-956 (2008)

9. Hoek, R.I.V.: The thesis of leagility revisited. Int. J. of Agile Management Systems 2(3), 196-201 (2000)

10. Wanddhwa, S., Mishra, M., Saxena, A.: A network approach for modeling and design of agile supply chains using a flexibility construct. Int. J. of Felxible Manufacturing System 19(4), 410-442 (2007)

11. Yusuf, Y.Y., Gunasekaran, A., Adeleye, E.O., Sivayoganathan, K.: Agile supply chain capabilities: Determination of competitive objectives. European J. of Operational Research 159, 379-392 (2004)

12. Lau Antonio, K.W., Yam, R.C.M., Tang, E.: The impact of product modularity on competitive capabilities and performance: An empirical study. Int. J. Production Economics 105, 1-20 (2007)

13. Ernst, R., Kamrad, B.: Evaluation of supply chain structures through modularized and postponement. European J. of Operation Research 124, 495-510 (2000)

14. Avneet, S., Wadhwa, S.: Flexible configuration for seamless supply chains: Directions towards decision knowledge sharing. Robotics and Computer-Integrated Manufacturing 25, 839-852 (2009)

15. Scholz-Reiter, B., Jagalski, T., Bendul, J.C.: Autonomous control of a shop floor based on bee's foraging behavior. In: Kreowski, H.J., Scholz-Reiter, B., Haasis, H.D. (eds.) Dynamics in Logistics. First Int. Conf., LDIC 2007, pp. 415-423. Springer, Heidelberg (2007) 
16. Vogel, A., Fischer, M., Jaehn, H., Teich, T.: Real-world shop floor scheduling by ant colony optimization. In: Dorigo, M., Di Caro, G.A., Sampels, M. (eds.) ANTS 2002. LNCS, vol. 2463, pp. 268-273. Springer, Heidelberg (2002)

17. Scholz-Reiter, B., Wirth, F., Freitag, M., Dashkovskiy, S., Jagaslki, T., de Beer, C., Rüffer, B.: Some remarks on the stability of manufacturing logistic networks. Stability margins. In: Proc. of the Int. Scientific Annu. Conf. on Operations Research, pp. 91-96. Springer, Bremen (2006)

18. Scholz-Reiter, B., de Beer, C., Freitag, M., Jagalski, T.: Bio-inspired and pheromone-based shop-floor control. Int. J. Computer Integrated Manufacturing 21(2), 201-205 (2008)

19. Nythuis, P., Wiendahl, H.P.: Logistic Production Operating Curves- Basic Model of the Theory of Logistic Operating Curves. CIRP Annals- Manufacturing Technology 55, 441444 (2006)

20. Scholz-Reiter, B., Mehrsai, A., Goerges, M.: Handling the Dynamics in Logistics- Adoption of Dynamic Behavior and Reduction of Dynamic Effects. Asian Int. J. of Science and Technology (AIJSTPME) 2(3), 99-110 (2009) 